\title{
Virtual aging and langerian psychology of possibility (revisiting the medical disempowering models of aging)
}

\begin{abstract}
The pervasiveness of the medical model of aging and its focus on physical health may have given rise to the assumption that an increase of age would result not only in the loss of youth and liveliness but also in the dissipation of the overall human competencies. This paper indicates how this assumption and similar propositions are embedded in a mindless understanding of health and aging. Drawing on numerous experimental research and findings, the paper argues that an increase of mindfulness would largely contribute to an enhancement of liveliness, health and vivacity.
\end{abstract}

Keywords: aging, mindfulness, mindlessness
Volume I Issue 3 - 2014

Sayyed Mohsen Fatemi, Ellen Langer

Department of Psychology, Harvard University, USA

Correspondence: Sayyed Mohsen Fatemi, Department of Psychology, Harvard University, Room 810, 33 Kirkland Street, WJH, Cambridge, MA 02138, USA, Tel 617-3099124, Emailsmfatemi@wjh.harvard.edu

Received: April 08, 2014 | Published: July 08, 2014

\section{Review}

The sovereignty of the medical model has generated a schema that an increase of age would be synonymous with a depletion of energy, an increase of illness and forgetfulness, a decrease of cognitive competencies, a disappearance of fervor and a lack of social skills. ${ }^{1,2}$

Although less than $6 \%$ of the elderly reside in nursing homes, the pervasive medical model gives out a prescriptive suggestion that older people are in dire need of extensive care as they cannot handle their own issues or they hardly have control and abilities to cope with the demands of daily life.

The schema produces derogatory implications in its practical domain in that working with the elderly is considered as something inferior as "Working with older people is seen as focusing on custodial activities that lack the "excitement" and status of other fields of social work practice". ${ }^{3}$ The schema and its associative labels have also given rise to a loss of voice for the elderly in that they consider themselves as disempowered, helpless, unable and incompetent.

It is in line with an understanding of the importance of language and its creational capabilities that Ray asks: "To what extent does language construct the field of gerontology? That is, what frames of reference structure interpretations? What Meanings are privileged? What meanings are ignored or discouraged? ${ }^{4}$

Studies by Langer ${ }^{5-7}$ demonstrate how entrapment in stereotypes and schemas may impede the process of looking at multiple available alternatives. These findings also suggest how aging can be mindlessly accepted as a process with negative implications such as loss of memory and cognition where as a mindful understanding of aging can open up the possibility of an increase in creativity and an improvement in memory. Langer's research on mindlessness and mindfulness also suggests that schemas on aging and their priming function, when accepted mindlessly, may largely contribute to producing responses and reactions on aging that confirm their inducing schemas. In other words, if the mindlessly accepted schemas delineate aging as something associated with depletion of energy and memory loss, the subsequent understanding of aging will move in line with the negative attitude towards aging whereas if the stereotypes be mindfully challenged, they would give rise to improvement of cognitive function ${ }^{7}$. Recent studies indicate that a mindful understanding of aging may also play a role in an increase of both cognitive and emotional performance.

A series of studies by Levy and her colleagues also indicate that older individuals exposed to negative-age-stereotype primes tended to perform worse than those exposed to positive-age-stereotype primes on four memory tasks. ${ }^{8}$ These results suggest not only that selfstereotypes of aging are capable of influencing a cognitive process in the aged but also that the process occurs without awareness.

Levy and colleagues also found that people's mindsets may contribute more to their health than the physiological factors we and our doctors typically focus on. They looked at the life spans of a group of more than 650 people in Oxford, Ohio, who in 1975 had been asked to respond to positive and negative statements about aging. They could agree or disagree with thoughts such as "Things keep getting worse as I get older", "As you get older, you are less useful", and "I am as happy now as I was when I was younger". Participants were then categorized as holding either a positive or a negative view of their health and aging. In checking the records of the participants more than twenty years after the survey, Levy and her colleagues found that those who viewed aging more positively lived, on average, 7.5years longer than those who were negative about it.

The focus on mindfulness with its essence as a proactive engagement in the present moment indicated that an increase of mindfulness can largely contribute to the retrieval and recollection of information. Langer's research ${ }^{5,7}$ demonstrates that with an increase of meaningfulness, choice oriented performance, control and engagement, people will have a better chance of retrieving and remembering the information.

Other findings including ethnographic studies indicate that elderly communities would play a significant role in facilitating the implications of wellbeing. Elderly communities, according to these studies, would implement and promote programs, ceremonies, rituals and rites that challenge the negative mindset of aging and encourage the elderly to question the negativity of aging as an element that can consolidate their togetherness with the community. The sense of togetherness would come up with a positive understanding of aging and will foster practical ways for "aging well". ${ }^{2,9-12}$ On the other hand, studies in older people in nursing homes demonstrate that the majority 
of these people feel that they have no control over their lives because of being old. ${ }^{13}$

Challenging this stereotype, Langer and Rodin ${ }^{14}$ instructed the director of a nursing home in Connecticut to encourage the residents to focus on their responsibility for their own lives and experience the importance of feeling in charge. This study indicated that an increase of feelings of control will have an impact on health, happiness and longevity.

It is interesting that if the control is not associated with an enduring control, the impacts turn out to be different. In a similar study, Schultz ${ }^{15}$ developed a similar condition with the difference that the elderly felt the control only for a short period of time whereas in Langer's study ${ }^{14}$ the elderly were given an enduring sense of control. The participants of Schultz group who experienced a sense of loss after the study suffered a loss of health which was avoided in Langer's study by building the treatment into their environment.

Mindfulness has a special focus on how language may create road blocks and deprive people of proceeding with alternative ways of living in the world.

There are four lessons from mindfulness research that may be helpful in counteracting the negative effects of stereotypes about the elderly. Based on the research, we need to focus our attention on

a. The criteria used to evaluate the elderly

b. Our inability to see past our own levels of development

c. The concept of change versus decay

A more mindful approach to old age, among both the elderly and among those who stereotype them ${ }^{7}$. This view may augur a revolutionary perspective as it revisits the illness model within health and its implications for the elderly. There seems to be scant research that has examined the concept of being well as an independent state of being without a focus on the illness models. ${ }^{16,17}$

We need to revisit the sovereignty of the controlling paradigms within the field of health and questions their prescriptive and proscriptive implications for health, longevity and the elderly.

"We can become effective health learners only by questioning the traditional ways we respond to medical information. We will be ready to seek a new way if we recognize that doctors can only know so much, that medicine is not an accumulation of absolute truths, that incurable really means indeterminate, and that our beliefs and most of the relevant external world are social constructions. ${ }^{7}$

One of the main components of Langerian mindfulness is challenging the medical oriented concept of aging. In line with this, Langerian mindfulness lies in questioning the mindlessly accepted obviousness of aging within the so-called physiological and illness models: aging cannot be explained merely through the perceptible physiological changes; it can be linked to a wide array of variables some of which have been highlighted in view of the medical model. Mindfulness focuses on a new understanding of aging away from the imposed bifurcation of the medical model.

In line with the same perspective on the constrictions of medial model, Horwitz ${ }^{18}$ writes:

The emergence and persistence of an overly expansive disease model of mental illness was not accidental or arbitrary. The widespread creation of distinct mental diseased developed in specific historical circumstances and because of the interests of specific social groups. By the time the DSM-III was developed in 1980, thinking of mental illness as discrete disease entities...offered mental health professionals many social, economic and political advantages. In addition, applying disease frameworks to a wide variety of behaviors and to a large number of people benefitted a number of specific special social groups including not only clinicians but also research scientists, advocacy groups, and pharmaceutical companies, among others. The disease entities of diagnostic psychiatry arose because they were useful for the social practices of various groups, not because they provided a more accurate way of viewing mental disorders.

The engagement in the medical model of aging and its concentration on the physical components of health has in the words of Vailant ${ }^{19}$ given rise to intensive volumes of research on "physical longevity" with scarcity of studies on "psychological longevity". ${ }^{20-23}$

Vailant ${ }^{19}$ discusses the successful aging through assessing health and its classification into physical health, psychological health, subjective health and objective health. Challenging the pervasive indices of health and its monopoly within physical health templates, Vailant ${ }^{19}$ argues that decay in the physical health is not necessarily tantamount to a dissipation of psychological health. Vailant ${ }^{19}$ considers the togetherness of four facets of health namely, psychical, psychological, subjective and objective health as the prerequisites for the good health and argues that biologically, you can be young or old for your chronological age. Second, physical health involves experiencing the biological ravages of age without feeling sick. Good self -care, high morale, intimate friends, mental health, and coping strategies often make the difference between being ill and feeling sick.

Langer's work on aging, mindlessness and mindfulness especially the findings on Counter clockwise (2009) demonstrate that aging is largely under the influence of cultivation and socialization. The recursive patterns of thinking about aging, according to Langer, ${ }^{7}$ is embedded within an imposing set of mindless assumptions that highlight aging and its associative implications with decay, degeneration and decline. Counterclockwise findings indicate how health and aging can be created through our own assumptions and how a change in the underlying assumptions of health and aging would contribute to a transformation in the nature of aging. The power of choices may help people explore the possibility of revisiting the components of aging in that we create aging through our own choices. An objective and subjective implementation of mindfulness, according to Counterclockwise, would give rise to choice oriented decisions and their implication for revitalization.

Through proposing a relationship between psychology of possibility and aging process, Langer ${ }^{7}$ readily challenges the constriction of aging and health within the accumulative medical model.

One may argue that our understanding of possibility might as well be contained within the mindless notions of possibility. The only reason that aging beyond the pervasive average recognized age is not possible is a mere entanglement within the recursive patterns of our perceptual and sensual constrictions. Our exposure to our socially created mindsets on aging may insist on the insensibility of aging extension beyond our frequently travelled tunnels of perceptual experiences and their leading interpretation on the extension, expansion and broadness of aging. The notion of possibility may ipso facto be embedded within a mindless definition of possibilities. A mindful fervor on re-exploring the process of psychological aging and its constitutive layers may open up the possibility of a creative aging process through which we create our aging. 
Mindfulness, according to entails an active state that is associated with creation of new knowledge, welcoming new horizons of information, noticing new things and being open towards the possibility of multiple perspectives. It is through an active state of mindfulness, Langer ${ }^{7}$ argues, that one would embrace the complexity, uncertainty, instability and uniqueness of the phenomena. Through numerous experiments, Langerian demonstrated how the mere reliance on positivist oriented knowing would lead to the monopoly of the legitimacy of one way of knowing namely the so-called rational way of knowing over numerous other ways of knowing. Langer's mindfulness (2009) advocates a tilt towards the position of not knowing since the fixed position of positivist knowing would hamper the exploration of an expansive array of epistemologies and locks the search for knowing in a pre-determined point. ${ }^{24}$

\section{Acknowledgments}

None.

\section{Conflicts of interest}

Author declares there are no conflicts of interest.

\section{Funding}

None.

\section{References}

1. May CP, Hasher L, Kane MJ. The role of interference in memory span. Mem Cognit. 1999;27(5):759-767.

2. Myerhoff B. Rites and Signs of Ripening: The Intertwining of Time Ritual, Time, and Growing Older. In: D Kertzer, J Keith (Eds.), Age and Anthropological Theory. Cornell University Press, London. 1984 p.344.

3. Kaufman AV, Kosberg, JI. Recruiting social work students into gerontogical careers: A challenge for social work education. Presented at the Annual Program Meeting of the Council on Social Work Education, NY. 2000.

4. Ray RE. Social influences on the older woman's life story. Generations. 2000;23(4):56-62.

5. Langer EJ. Mindfulness. Reading, Addison-Wesley. 1989.

6. Langer EJ. The power of mindful learning. Addison Wesley. 1997.

7. Langer E. Counter clockwise: Mindful health and the power of possibility. Ballentine Books, New York, USA. 2009.

8. Levy B, Langer E. Aging free from negative stereotypes: Successful memory in China and among the American deaf. J Pers Soc Psychol. 1994;66(6):989-997.
9. Fitzgerald F. Cities on a hill: a journey through contemporary american culture. (1st edn), Simon and Shuster, NewYork, USA. 1986. p.414.

10. Hazen H. 'Course' vs. 'Cycle': On the Understanding of Understanding Aging. In: JF Gubrium (Ed.), Aging, Self; and Community. JAI Press, Greenwich, CT, UK. 1992. p. 3-13.

11. Hochschild AR. The unexpected community: portrait of an old age subculture. University of California Press, Berkeley, Los Angeles, London, UK. 1973.

12. Jerome D. “That's What It's All About: Old People's Organizations as a Context for Aging." In: JF Gubrium (Ed.), Aging, Self; and Community. JAI Press, Greenwich, CT, UK. 1992. p. 225-235.

13. Raps CS, Peterson C, Jonas M, et al. Patient behavior in hospitals: helplessness, reactance, or both? J Pers soc Psychol . 1982;42(6):1036-1041.

14. Langer EJ, Rodin J. The effects of choice and enhanced personal responsibility for the aged: A field experiment. J Pers Soc Psychol . 1976;34(2):191-198.

15. Schultz R. Effects of control and predictability on the physical and psychological wellbeing of the institutionalized aged. J Pers Soc Psychol. 1976;33(5):563-573.

16. Medich CJ, Stuart E, Chase SK. Healing through integration: promoting wellness in cardiac rehabilitation. J Cardiovasc Nurs. 1997;11(3):66-79.

17. Paul L, Weinert C. Wellness profile of midlife women with a chronic illness. Public Health Nurs. 1999;16(5):341-350.

18. Horwitz AV. Creating mental illness. University of Chicago University Press, Chiago, USA. 2000. p.315.

19. Vailant GE. Positive aging. In: Linely PA \& Joseph S (Eds.), Positive Psychology in Practice. John Wiley \& Sons, Inc., New Jersey, USA. 2004.

20. Baltes PB, Mayer KV. The Berlin Aging Study. Cambridge University Press, Cambridge, UK. 1999. p.552.

21. Dawber TR. The Framingham study. Harvard University Press, Cambridge, UK. 1980. p.265.

22. Fries JF. Aging: Natural death and the compression of morbidity. $N$ Engl $J$ Med . 1980;303(3):130-135.

23. Rowe J W, Kahn RL. Successful aging. Dell, New York, USA. 1999.

24. Fatemi SM. Exemplifying a Shift of Paradigm: Exploring the Psychology of Possibility and Embracing the Instability of Knowing. In: Amanda le, Ngnoumen CT, Langer EJ (Eds.), The Wiley Blackwell Handbook of Mindfulness. John Wiley \& Sons, Chichester, UK. 2014. p.115-138. 